\title{
A SURVEY OF CONSUMER SATISFACTION WITH MOBILE PAYMENT SYSTEM: AN EMPIRICAL STUDY OF A UNIVERSITY IN ZHEJIANG PROVINCE
}

\author{
Li-Wei Lin ${ }^{*}{ }^{\square}$, Zhu-Ji ${ }^{2}$, Xuan -Gang ${ }^{3}$ \\ ${ }^{* 1}$ School of Information, Zhejiang University of Finance and Economics Dongfang College, \\ Zhejiang, China \\ 2, 3 Zhejiang University of Finance and Economics Dongfang College, Zhejiang, China
}

DOI: https://doi.org/10.29121/granthaalayah.v9.i2.2021.3582

Article Type: Research Article

Article Citation: Li-Wei Lin, Zhu-Ji, and Xuan -Gang. (2021). A SURVEY OF CONSUMER SATISFACTION WITH MOBILE PAYMENT SYSTEM: AN EMPIRICAL STUDY OF A UNIVERSITY IN ZHEJIANG PROVINCE. International Journal of Research -GRANTHAALAYAH, 9(2), 266-274.

https://doi.org/10.29121/granthaa layah.v9.i2.2021.3582

Received Date: 30 January 2021

Accepted Date: 28 February 2021

Keywords:

Mobile Payment Convenience

Security

Credibility

Consumer Satisfaction

\section{ABSTRACT}

Based on the extended study of online payment and settlement, we investigated interesting research on the use of online payment by students. This study mainly investigates the use of mobile payment consumers in a university in Haining, Zhejiang Province in 2020. The research object of this time is a university in Haining, Zhejiang Province. Mobile payment is very popular among young people. In this study, a college student was taken as the object of investigation, with 436 samples $\mathrm{N}$, and the effective questionnaires reached $96 \%$. The correlation was investigated through factor analysis. In recent years, mobile payment system has been more and more popular and used by consumers. Mobile payment is mainly applied to online and offline payment such as two-dimensional barcode shopping (purchased from vending machines and supermarkets), payment by public transportation (bus and subway), and game of grabbing red envelopes. In this study, Likert five-point scale was used to conduct factor analysis, and reliability and validity analysis of this action payment on consumer satisfaction was conducted. Convenience, security, credibility and consumer satisfaction brought by mobile payment system are the main research directions of this study. In the process of research design, we designed three hypothesis models, hoping to verify whether the hypothesis has causal correlation through this model.

\section{INTRODUCTION}

Traditionally, the third-party payment of e-commerce belongs to the payment method on the online platform. In recent years, payment technologies have been continuously innovated. In addition to online payment through computer platforms, third-party payment has also started to combine mobile payment (mobile payment). This study investigated the satisfaction with mobile payment among students in a university in Haining, Zhejiang Province, mainly to understand whether the convenience, security and credibility of mobile payment will cause consumers' satisfaction with the use of mobile payment. Our research breaks the traditional e-commerce. Many scholars discuss the operation of e-commerce application on computer platform. We observe that students in a university in Haining, Zhejiang Province like to pay through its mobile payment function (such as Alipay, WeChat payment, etc.). This set of mobile payment transaction mechanism, belongs to the extension of third-party payment, we can clearly understand that the consumer satisfaction after use is one of the key success factors. When consumers use their

(C) 2021 The Author(s). This is an open access article distributed under the terms of the Creative Commons Attribution License, which permits unrestricted use, distribution, and reproduction in any medium, provided the original author and source are credited. 
online payment for transactions, they need to trust the role of the third party impartial unit, and the seller will pass it to the consumer through the third party impartial mechanism. This set of online payment becomes a need for a good management mechanism before use. This trading system can mainly reduce the uncertainty risk of its trading system and indirectly take a good relationship between the buyer and seller. Heide(1994) put forward how to establish its transaction relationship and management as an important key factor. This management mechanism will determine whether its consumers are willing to continue using its mobile payment system. We are in the process of research perspective its consumers can continue to use the most critical factors in the use, pay action can be provided to the consumer safety and guarantee the security of its consumers to use the system, leading to its consumers are willing to continue to use, so both sides to build the relationship, the main reason is that pay can provide to the consumers' trust and commitment relationship, further to achieve customer satisfaction. Through the perspective of trading theory, our research can clearly understand the process and causality of trading theory, and the ultimate goal is to achieve the establishment of a good trading relationship between both parties. The foundation of our research on relationship trust is extended through the conceptual foundation of the school of supply chain management, mainly to observe whether the interaction between the payment system party and consumers can reach a mature stage. Sabel(1993) proposed the definition of trust is mutual trust rather than the use of other loopholes to obtain the purpose of its exchange. Through its long-term observation, this study finds that in order to establish the satisfaction and trust between mobile payers and consumers, relevant factors such as the security of mobile payment, the convenience of mobile payment, and the credibility of mobile payment should be considered in the system, so as to establish a long-term trust relationship between consumers and both parties. Through the contractual relationship established before the consumer uses the action to pay, we enable the consumer to take the action of its protection, and indirectly obtain the satisfaction of the consumer. The biggest difference between our research and the previous research by many scholars lies in the fact that the usual payment method of third-party payment is mainly virtual online payment. By combining the payment method of mobile phone application, our research enables consumers not only to pay online, but also to pay offline by combining the payment method of mobile phone.

Our research team observed that pay action has broken the traditional mode of e-commerce transactions, mainly through the platform of the traditional way can be on the platform of online trading, we observed with the insight to action can pay the payment with mobile phone binding, but many scholars debate whether questions about the safety of consumers (such as encryption to protect personal data were leaked, trade in, a hacker intrusion action payment platform, etc.). As we mentioned in the previous paragraph, from the perspective of the management mechanism of mobile payment, we mentioned how to make mobile payment system establish mutual trust and commitment with consumers, and system security becomes a very important concept and factor. We can learn that the early e-commerce transaction behavior is through the encryption behavior of SSL to protect consumers online payment behavior, and in the current action payment in addition to the system protection behavior, but also increased the user side fingerprint identification and password confirmation two security protection measures. Mayer(1995) proposed that the trust relationship can be completed and implemented through the expectation of the other party when the activities of one party are relatively weak. Mobile payment security system, we design according to the needs of consumers to consider the design, the ultimate goal we observe that mobile payment can provide consumers with a good secure transaction platform. From the viewpoints of these scholars on trust theory, we can clearly understand that the system security of mobile payment will have its impact on the use of consumers. We hope that through this design process, we can verify the causal effect that can produce its correlation.

Many scholars will talk about the literature of creditworthiness, and we can look at the literature to understand the creditworthiness. Many scholars mentioned in the stage of e-commerce that the concept of reputation appears on social networking sites and social media, such as WeChat, Facebook and other communication software platforms. Through the links of social networking, consumers can evaluate the reputation of their enterprises. Through its information sharing and information transmission, we hope to convey the ultimate goal of its reputation rating message. Liang and Turban (2011) proposed that e-commerce can be developed into social commerce. In this study, we found that the system function of mobile payment needs to provide a good credibility, which is similar to the website of e-commerce platform, and consumers need to get credit recognition. Such information sharing and openness can mainly create its credibility and reputation. This mobile payment system is mainly able to get the support and system services of consumers, and this series of system mechanisms also create whether consumers recognize their mobile payment system. In this way, consumers can get their recognition and commitment of action payment through word-of-mouth spread in the community.

International Journal of Research -GRANTHAALAYAH 
The biggest difference in this study is that the content created by consumers for mobile payment supports its entire operation mode. We can learn that through the active participation of consumers to get the whole action to pay for the positive behavior of business activities. Nambisan(2002) proposed Consumer Support Business and New Product Development Program.

\section{THEORY AND DEVELOPMENT HYPOTHESIS}

In this study, factor analysis was used to verify whether the correlation could be established. This study clearly designs three hypothetical relationships in Figure 1. We explored the causal relationship through three hypotheses, with the main purpose of obtaining the results of investigation verification. This study examined whether the convenience of mobile payment, the security of mobile payment, and the credibility of mobile payment had a correlation with consumer satisfaction.

In the model of Figure 1, this study directly affects the trust relationship between the two parties through the action payment relationship. Anderson and Weitz(1992) mentioned that trust theory can be linked to social transaction theory and establish the relationship between business.

In recent years, due to the popularity of social networking sites, information has become more and more transparent. As we mentioned in the previous introduction, consumers can access any mobile payment information through social networking sites. How to build credibility with action pay? Many action pay organizations build a team or spend a lot of time building credibility. Napoles(1988) proposed that the corporate image symbol can be represented by the assets of the enterprise as a whole. Henderson et al. (2003) proposed that corporate image marks can connect relevant stakeholders of the organization and confirm the competitiveness of the enterprise. Therefore, we examine whether the creditworthiness has a positive correlation with consumers through action payment. On the other hand, we look at the whole social network from the perspective of social commerce. Only a good reputation can make the whole operation pay. Kaiser and Muller-Seitz(2008) mentioned that blog forums are conducive to knowledge sharing and innovation.

The research model is as follows:

H1: Whether the convenience of mobile payment is relevant to consumer satisfaction

$\mathrm{H} 2$ : Whether the security of mobile payment is relevant to consumer satisfaction

H3: Whether the credibility of mobile payment is relevant to consumer satisfaction

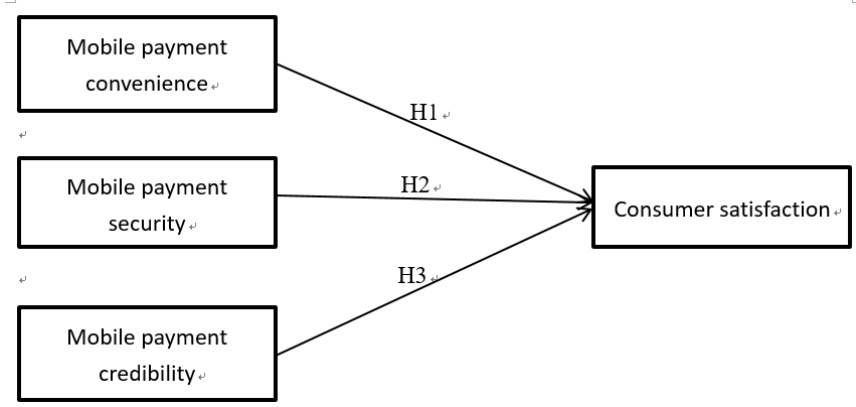

Figure 1: Hypothesis model

\section{STUDY DESIGN AND DATA COLLECTION}

\subsection{FACTOR ANALYSIS}

\subsubsection{SAMPLE NUMBER TEST}

Minimum sample size: $24 * 5=120$

The number of data pieces is 417 , which meets the minimum sample requirements 


\begin{tabular}{|l|l|}
\hline Input data type & Original material \\
\hline Number of records read & 436 \\
\hline Number of records used & 417 \\
\hline Significant identification of $\mathbf{N}$ & 417 \\
\hline
\end{tabular}

\subsubsection{HYPOTHESIS TESTING}

Since the number of samples was $>50$, the D values of Kolomogorov were observed, and the P values were all $<0.05$, so there was no normal distribution. Therefore, the central limit theorem was used to converge the data.

\subsubsection{FITNESS TEST}

Since the overall MSA value was $>0.5$ and individual MSA was also BBB $>5$, it met the fitness test.

\begin{tabular}{|l|l|l|l|l|}
\hline \multicolumn{5}{|c|}{ Kaiser sampling adequacy measure: overall MSA=0.91981215 } \\
\hline C22 & C24 & C26 & C28 & C30 \\
\hline 0.89220411 & 0.91824622 & 0.91837465 & 0.88475269 & 0.94229832 \\
\hline
\end{tabular}

\subsubsection{NUMBER OF DETERMINANTS}

Since there are only four eigenvalues $>$ and 1, there are four factors.

Table 1

\begin{tabular}{|c|c|c|c|c|}
\hline \multicolumn{5}{|c|}{ The eigenvalues of the correlation matrix : Total=24 Average=1 } \\
\hline & The eigenvalue & Discrepancy & The proportion & The cumulative \\
\hline 1 & 9.87767083 & 8.03466903 & 0.4116 & 0.4116 \\
\hline 2 & 1.84300180 & 0.47487619 & 0.0768 & 0.4884 \\
\hline 3 & 1.36812561 & 0.30801150 & 0.0570 & 0.5454 \\
\hline 4 & 1.06011411 & 0.17026061 & 0.0442 & 0.5895 \\
\hline 5 & 0.88985350 & 0.02769034 & 0.0371 & 0.6266 \\
\hline 6 & 0.86216316 & 0.02336921 & 0.0359 & 0.6625 \\
\hline 7 & 0.83879395 & 0.11157476 & 0.0349 & 0.6975 \\
\hline 8 & 0.72721919 & 0.05643707 & 0.0303 & 0.7278 \\
\hline
\end{tabular}

\subsubsection{DETERMINING FACTOR LOAD VALUE}

According to the four factors identified, find the appropriate factor for each variable through the rotation axis. Factor1 : c2,c4,c6,c8,c10,c12,c14,c16,c18,c20,c34

Factor2 : c22,c24,c28,c30,c32,c36

Factor3:c38,c40,c42,c44

Table 2

\begin{tabular}{|c|c|c|c|c|}
\hline $\begin{array}{c}\text { The factor model of } \\
\text { rotation }\end{array}$ & $\begin{array}{c}\text { The factor model of } \\
\text { rotation }\end{array}$ & $\begin{array}{c}\text { The factor model of } \\
\text { rotation }\end{array}$ & $\begin{array}{c}\text { The factor model of } \\
\text { rotation }\end{array}$ & $\begin{array}{c}\text { The factor model of } \\
\text { rotation }\end{array}$ \\
\hline C2 & Factor1 & Factor2 & Factor3 & Factor4 \\
\hline & 0.70200 & 0.20608 & 0.29470 & 0.09494 \\
\hline
\end{tabular}


A Survey of Consumer Satisfaction with Mobile Payment System: An Empirical Study of a University in Zhejiang Province

\begin{tabular}{|c|c|c|c|c|}
\hline C4 & 0.71123 & 0.06207 & 0.28965 & 0.11004 \\
\hline C6 & 0.68453 & 0.18230 & 0.15328 & 0.15980 \\
\hline C8 & 0.65941 & 0.34158 & 0.20325 & 0.01063 \\
\hline C10 12 & 0.55800 & 0.39088 & 0.23121 & 0.14207 \\
\hline C14 & 0.63619 & 0.31102 & 0.25123 & 0.12748 \\
\hline C16 & 0.52198 & -0.10388 & -0.05759 & 0.21411 \\
\hline C18 & 0.62200 & 0.28128 & 0.10240 & -0.02151 \\
\hline C20 & 0.62090 & 0.35295 & 0.20136 & 0.00195 \\
\hline C22 & 0.53625 & 0.49104 & 0.30783 & 0.04199 \\
\hline C24 & 0.51993 & 0.26820 & 0.48433 & 0.10964 \\
\hline C28 & 0.26083 & 0.71917 & 0.12068 & 0.11554 \\
\hline C30 & 0.27214 & 0.69924 & 0.13042 & 0.10383 \\
\hline C36 & -0.02135 & 0.62590 & -0.02350 & 0.48489 \\
\hline C38 & 0.23776 & 0.52645 & 0.33735 & 0.22420 \\
\hline C40 & 0.24909 & 0.58932 & 0.37825 & 0.01029 \\
\hline C42 & 0.28716 & 0.52170 & 0.40819 & 0.21781 \\
\hline C44 & 0.19567 & 0.21339 & 0.78320 & 0.11618 \\
\hline C26 & 0.12798 & 0.26430 & 0.75150 & 0.16096 \\
\hline C46 & 0.43050 & 0.17991 & 0.61423 & 0.25116 \\
\hline C48 & 0.31691 & 0.01136 & 0.65730 & 0.39482 \\
\hline & 0.22191 & 0.36850 & 0.20446 & 0.70938 \\
\hline
\end{tabular}

\subsubsection{DECIDING FACTOR SCORE VALUE}

Since the factor is derived from a group of random variables, the factor can also be estimated from the group of random variables, which can be expressed as follows:

$F_{j}=\sum_{i=1}^{m} w_{j t} X_{t}^{*}=w_{j 1} X_{1}^{*}+w_{j 2} X_{2}^{*}+\cdots+w_{j m} X_{m}^{*}$

Factor1

:c2*0.195+c4*0.229+c6*0.225+c8*0.169+c10*0.111+c12*0.156+c14*0.261+c16*0.187+c20*0.063+c34*0.062 $=1.1391$

Factor2 : c22*0.323+c24*0.309+c28*0.295+c30*0.172+c32*0.229+c36*0.15=0.9372

Factor3 : c38*0.424+c $40 * 0.401+\mathrm{c} 42 * 0.234+\mathrm{c} 44 * 0.282=0.9632$

Factor4 : c26*0.285+c46*0.379+c48*0.497 $=0.8373$

Table 3

\begin{tabular}{|c|c|c|c|c|}
\hline \multicolumn{5}{|c|}{ Standardized scoring coefficients } \\
\hline & Factor1 & Factor2 & Factor3 & Factor4 \\
\hline C2 & 0.19497 & -0.07819 & -0.01117 & -0.01747 \\
\hline C4 & 0.22904 & -0.16305 & 0.00064 & 0.01355 \\
\hline C6 & 0.22519 & -0.07709 & -0.11188 & 0.05774 \\
\hline C8 & 0.16903 & 0.03176 & -0.06409 & -0.07283 \\
\hline C10 & 0.11139 & 0.05779 & -0.05713 & -0.00106 \\
\hline C12 & 0.15613 & -0.00391 & -0.04705 & -0.00256 \\
\hline C14 & 0.26104 & -0.18449 & -0.18669 & 0.17470 \\
\hline C16 & 0.18731 & 0.02380 & -0.10763 & -0.06491 \\
\hline
\end{tabular}


Li-Wei Lin, Zhu-Ji, and Xuan -Gang

\begin{tabular}{|l|c|c|c|c|}
\hline C18 & 0.15053 & 0.04736 & -0.05644 & -0.08029 \\
\hline C20 & 0.06321 & 0.12188 & 0.00574 & -0.09687 \\
\hline C34 & 0.06180 & -0.03555 & 0.14464 & -0.05913 \\
\hline C22 & -0.05705 & 0.32254 & -0.10476 & -0.04521 \\
\hline C24 & -0.05061 & 0.30922 & -0.09552 & -0.05200 \\
\hline C28 & -0.12123 & 0.29532 & -0.20162 & 0.23540 \\
\hline C30 & -0.07579 & 0.22928 & 0.11037 & -0.15047 \\
\hline C32 & -0.09603 & 0.22928 & 0.11037 & -0.15047 \\
\hline C36 & -0.06976 & 0.15039 & 0.08772 & -0.01098 \\
\hline C38 & -0.13384 & -0.04530 & 0.42383 & -0.11509 \\
\hline C40 & -0.16518 & -0.00463 & 0.40133 & -0.08721 \\
\hline C42 & -0.01389 & -0.10582 & 0.23435 & 0.01705 \\
\hline C44 & -0.00874 & -0.20470 & 0.28249 & 0.12359 \\
\hline C26 & -0.01565 & 0.05632 & -0.08645 & 0.28456 \\
\hline C46 & -0.05085 & -0.03040 & -0.02500 & 0.37924 \\
\hline C48 & 0.01488 & -0.14137 & -0.08980 & 0.49718 \\
\hline
\end{tabular}

\subsubsection{RELIABILITY AND VALIDITY TEST AND SENSITIVITY ANALYSIS OF EACH FACTOR}

Cronbach alpha number was created by Cronbach(1951). He used alpha number to represent the internal consistency reliability of the scale. The higher the alpha number, the better the internal consistency of the scale.

Cronbach alpha verified the internal consistency of the scale, and the overall Cronbach alpha value of the scale was 0.93 .

\begin{tabular}{|l|l|}
\hline 24 & $\mathrm{c} 2 \mathrm{c} 4 \mathrm{c} 6 \mathrm{c} 8 \mathrm{c} 10 \mathrm{c} 12 \mathrm{c} 14 \mathrm{c} 16 \mathrm{c} 18 \mathrm{c} 20 \mathrm{c} 22 \mathrm{c} 24 \mathrm{c} 26 \mathrm{c} 28 \mathrm{c} 30 \mathrm{c} 32 \mathrm{c} 34 \mathrm{c} 36$ \\
variables: & $\mathrm{c} 38 \mathrm{c} 40 \mathrm{c} 42 \mathrm{c} 44 \mathrm{c} 46 \mathrm{c} 48$
\end{tabular}

\begin{tabular}{|l|l|}
\hline \multicolumn{2}{|l|}{ Cronbach's coefficient Alpha } \\
\hline variable & Alpha \\
\hline Original & 0.923015 \\
\hline Standardized & 0.935296 \\
\hline
\end{tabular}

(1) The Cronbach alpha of Factor1 is 0.904

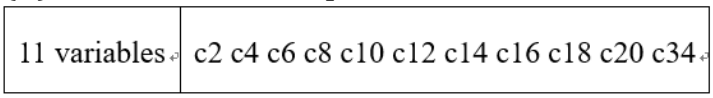

\begin{tabular}{|l|l|}
\hline \multicolumn{2}{|l|}{ Cronbach's coefficient Alpha } \\
\hline variable & Alpha \\
\hline Original & 0.866791 \\
\hline Standardized & 0.904621 \\
\hline
\end{tabular}

(3) The Cronbach alpha of Factor3 is 0.83

\begin{tabular}{|l|l|}
\hline 4 variables & c38 c40 c42 c44 \\
\hline \hline Cronbach's coefficient Alpha \\
\hline variable & Alpha \\
\hline Original & 0.835175 \\
\hline Standardized & 0.836173 \\
\hline
\end{tabular}

(2) The Cronbach alpha of Factor2 is 0.82

\begin{tabular}{|l|l|}
\hline 6 variables & C22 c24 c28 c30 c32 c36 \\
\hline \hline Cronbach's coefficient Alpha \\
\hline variable & Alpha \\
\hline Original & 0.817452 \\
\hline Standardized & 0.820161 \\
\hline
\end{tabular}

(4) Factor4's Cronbach alpha is 0.711

\begin{tabular}{|l|l|}
\hline 3 variables & C26 c46 c48 \\
\hline Cronbach's coefficient Alpha \\
\hline variable & Alpha \\
\hline Original & 0.710614 \\
\hline Standardized & 0.711564 \\
\hline
\end{tabular}


Since Cronbach alpha is all 0.6, sensitivity analysis is not needed.

\subsubsection{NAMING OF FACTORS}

Table 4: Mobile payment name

\begin{tabular}{|c|c|}
\hline Factors named & The name of the variable \\
\hline Consumer satisfaction & $\begin{array}{l}\text { C2 The mobile payment makes consumers feel very convenient to use } \\
\text { C4 The mobile payment provides users with quick and agile services } \\
\text { C6 The mobile payment will not respond to user requests because the system is busy } \\
\text { C8 The attitude of the action payment to the user service is friendly and friendly } \\
\text { C10 The mobile payment can provide users with a complete mechanism } \\
\text { C12 The mobile payment can design the best mechanism for consumers to think about } \\
\text { C14 from previous interaction and transaction experience, the action payment } \\
\text { transaction process is honest and reliable } \\
\text { C16 from the previous interaction and transaction experience, the action payment } \\
\text { mechanism and management is very perfect } \\
\text { C18 from previous experience with C18 interactions and transactions, this action } \\
\text { payment service is to be expected } \\
\text { C20 draws from past interaction and transaction experience, the action pays to } \\
\text { understand the customers who need to be served } \\
\text { C34 transaction security comes from the fact that the action payment provides the } \\
\text { successful outcome of past transactions }\end{array}$ \\
\hline $\begin{array}{c}\text { Mobile payment } \\
\text { convenience }\end{array}$ & $\begin{array}{l}\text { C22 mobile payment is very similar and convenient to the online payment of third- } \\
\text { party payment } \\
\text { C24 mobile payment can be very convenient in the physical stores to spend and } \\
\text { shopping } \\
\text { C28 mobile payment allows quick payment on mass transport } \\
\text { C30 mobile payment can be easily paid from vending machines } \\
\text { C32 mobile payment convenience has been integrated with our lives } \\
\text { C36 mobile payments can make it easier to spend money in different countries }\end{array}$ \\
\hline $\begin{array}{l}\text { Mobile payment } \\
\text { security }\end{array}$ & $\begin{array}{l}\text { C38 mobile payment transaction system is able to provide me with job protection } \\
\text { C40 I am quite satisfied with the system security provided by the action payment } \\
\text { C42 The mobile payment can provide me with detailed information about the } \\
\text { operation and transaction process } \\
\text { C44 Internet banks put more effort into transaction security mechanism than other } \\
\text { non-Internet banks }\end{array}$ \\
\hline $\begin{array}{l}\text { Mobile payment } \\
\text { credibility }\end{array}$ & $\begin{array}{c}\text { C26 The action payment has the influence of credibility and public praise in the forum } \\
\text { evaluation } \\
\text { C46 The action payment can solve the loss and risk caused by consumers in the } \\
\text { transaction process } \\
\text { C48 Mobile Pay has become a well-known mobile payment brand }\end{array}$ \\
\hline
\end{tabular}

\section{DISCUSS AND APPLY PRACTICES}

This research topic is mainly applied to our daily life in action payment. We have observed that mobile payment is becoming more and more popular among young people in recent years. We have mainly targeted a sample of college students in Guangdong Province. We have observed why college students use the mobile payment function, and the main reason is that the convenience, system security and credibility of mobile payment will directly affect the satisfaction of consumers. There are many ways of mobile payment, including scanning payment with WeChat 2D barcode, combined with online payment of bank account and other fingerprint mobile payment functions. In this study, we conducted factor analysis through SAS software, mainly hoping to observe whether the causal relationship is established. The sample number of this time is 436 . Through the confirmatory analysis of the sample number, we can observe that the convenience of mobile payment, the security of mobile payment, and the credibility of mobile 
payment will have a correlation with consumer satisfaction. From the factor naming and variable design in the previous paragraph, we can clearly see that the propositional project designed is mainly designed for different factors and applied verification. We hope to examine whether these causal variables can have a positive correlation effect on the effect variables. From the research, we can directly see that these three hypotheses can directly verify that the convenience of payment for actions, the security of payment for actions, and the credibility of payment for actions will directly have a positive correlation effect on consumer satisfaction. This study aims at the current research, deduces and designs from the above theories to make new contributions.

\section{CONCLUSIONS AND FUTURE RESEARCH}

The biggest contribution of this study is that the traditional e-commerce online shopping is through the thirdparty online payment to settle and use. Our research this time is to complete the shopping payment in the store through the mobile payment method, such payment method also breaks the traditional online payment. The arrival of mobile payment indirectly integrates online and offline shopping methods, aiming at different consumers to make payment methods. Our research through innovative approach to analysis, we mainly make up before the gap, such as (1) action payment and online payment (2) the difference of the action on how to design the management system (3) the application and practice of action to pay pay for consumers to purchase behavior change (for example, the evaluation mechanism or information information recommendation). This time, our survey target is a college student in Haining, Zhejiang Province. We conducted a Likert five-point scale reliability and validity survey on the questionnaire topic we designed. We are mainly going to observe action payments to do exploratory analysis of consumer satisfaction behavior.

This study conducted an investigation through a college student in Haining, Zhejiang Province. However, there are still some limitations that cannot be done best. The following suggestions can be helpful for future research:

\subsection{RESTRICTIONS ON THE DISTRIBUTION OF QUESTIONNAIRES}

The object of the questionnaire in this study is only the students of a university in Haining, Zhejiang. It is suggested that future researchers could expand the survey to the students in Haining, Zhejiang, so as to clearly understand the views of the whole college students in Foshan on mobile payment.

\subsection{STUDY THE LIMITATIONS OF VARIABLES}

This study is mainly aimed at the security, convenience, credibility, consumer satisfaction of mobile payment platform to do investigation and measurement. Due to the relationship between human resources, material resources and financial resources, we can only investigate a college student in Foshan in a small area, and the design of variables does not take into account more angles. We suggest that future researchers can explore and analyze the business model variables of mobile payment success, because the model of social business success is a variable worth exploring.

The biggest difference of this study is that our research is not limited to the third-party payment of e-commerce, but the upgraded version of third-party payment. In the review process of the third payment literature, few scholars could mention action payment, which is also the biggest contribution and difference of our study. Many scholars discuss the process of the third-party payment, but the biggest difference in our study is that we observe the consumers' views on the payment after using the third-party payment. We suggest that future researchers should be able to look into the variable of mobile payment, and should not be limited to online third-party payment. This study breaks the traditional view that the third-party payment only has online transaction. The third-party payment combined with mobile payment can also complete the offline transaction process. Offline trading mode will be a good research direction in the future, which is also our suggestion for subsequent researchers.

\section{SOURCES OF FUNDING}

This research received no specific grant from any funding agency in the public, commercial, or not-for-profit sectors.

International Journal of Research -GRANTHAALAYAH 


\section{CONFLICT OF INTEREST}

The author have declared that no competing interests exist.

\section{ACKNOWLEDGMENT}

This research was supported by the Zhejiang University of Finance and Economics Dongfang College, under contract Higher Education Research Project of Zhejiang Province Association for Higher Education in 2020 (NO : 2020JK05).

\section{REFERENCES}

[1] Heide, J. B. (1994). Interorganizational governance in marketing channels. The Journal of Marketing, 71-85.

[2] Sabel, C. F. (1993). Studied trust: building new forms of cooperation in a volatile economy. Human relations, 46(9), 1133-1170.

[3] Mayer, R. C., Davis, J. H., \& Schoorman, F. D. (1995). An integrative model of organizational trust. Academy of management review, 20(3), 709-734.

[4] Liang, T. P., Ho, Y. T., Li, Y. W., \& Turban, E. (2011). What drives social commerce: The role of social support and relationship quality. International Journal of Electronic Commerce, 16(2), 69-90.

[5] Nambisan, S. (2002). Designing virtual customer environments for new product development: Toward a theory. Academy of Management Review, 27(3), 392-413.

[6] Anderson, E., \& Weitz, B. (1992). The use of pledges to build and sustain commitment in distribution channels. Journal of marketing research, 18-34.

[7] Napoles, V., \& Napoles, V. (1988). Corporate identity design. New York, NY.: Van Nostrand Reinhold.

[8] Henderson, Pamela W., \& Cote, Joseph A. (2003). Guidelines for selecting or modifying logos, Journal of marketing, 62(April), 14-30.

[9] Kaiser, S., \& Müller-Seitz, G. (2008). Leveraging lead user knowledge in software development-The case of weblog technology. Industry and Innovation, 15(2), 199-221. 